\title{
Outcomes and Incidence of Deep Bone Infection in Grade III Diaphyseal Open Tibial Fractures: Circular Fixator vs Intramedullary Nail
}

\author{
Ibrahim Natalwala ${ }^{1}$, Cher Bing Chuo ${ }^{2}$, Isla Shariatmadari ${ }^{3}$, Gavin Barlow $^{4}$, Elizabeth Moulder ${ }^{5}$, Joanna Bates ${ }^{6}$, \\ Hemant Sharma ${ }^{7}$
}

\begin{abstract}
Introduction: High-energy grade III open fractures of tibia are associated with significant complications and generate debate over the ideal fixation method. This study compares the clinical outcomes for circular frame fixation (CFF) vs intramedullary nail fixation (IMF) in grade III open tibial fractures.

Materials and methods: Single-centre retrospective study of patients admitted from January 2008 to December 2016. All patients with grade III open diaphyseal tibial fractures (AO 42 A, B, C), treated with either CFF or IMF, were included. The primary outcome was deep bone infection (DBI). Secondary outcomes were delayed or non-union, secondary intervention, and amputation.

Results: A total of 48 limbs in 47 patients had CFF, and 25 limbs in 23 patients had IMF. Median time to definitive fixation was significantly longer for CFF at 9 days (IQR 3-13) compared to IMF at 1 day (IQR $0-3.5)(p<0.001)$. The DBI rate was significantly lower $(2$ vs $16 \%)$ in the CFF group $(p=0.04)$. There were 14 limbs (29\%) with delayed or non-union in the CFF group vs 5 limbs (20\%) in the IMF group. In the CFF group, significantly more limbs required bone grafting for delayed or non-union $(p=0.03)$. However, there was a greater proportion of limbs in the CFF group with segmental fractures or bone loss (46 vs $4 \%$ ) and these high-energy fracture patterns were associated with secondary bone grafting $(p=0.005)$, and with delayed or non-union $(p=0.03)$. A subgroup analysis of patients without segmental fractures or bone loss treated with either CFF or IMF showed no significant difference in secondary bone grafting $(p>0.99)$ and delayed or non-union rates $(p=0.72)$. Overall, one patient in each group went on to have an amputation.

Conclusion: Our study found that CFF had a lower rate of DBI compared to IMF. Injuries with high-energy fracture patterns (segmental fractures or bone loss) were more likely to have delayed or non-union and require secondary bone grafting. These factors should be considered when selecting the appropriate method of definitive fixation.

Keywords: Circular frame, Intramedullary nail, Open fracture, Tibia.

Strategies in Trauma and Limb Reconstruction (2021): 10.5005/jp-journals-10080-1536
\end{abstract}

\section{INTRODUCTION}

Open tibial fractures are complex injuries requiring urgent assessment and treatment, which has been formalised by the British Orthopaedic Association (BOA) and British Association of Plastic Reconstructive and Aesthetic Surgeons (BAPRAS) Standards for the Management of Open Fractures. ${ }^{1}$ In the United Kingdom (UK), open fractures of the tibial diaphysis have an incidence of 3.4 per 100,000 persons each year with bimodal peaks in young males and older females. Approximately $45 \%$ of open tibial fractures are classed as Gustilo-Anderson (GA) grade III. ${ }^{2}$

These injuries often result in substantial bone comminution, periosteal stripping, soft tissue loss, and contamination and are susceptible to bacterial ingress with biofilm formation and hence an increased risk of deep bone infection (DBI). ${ }^{3}$ Treatment of open lower limb fractures has a median cost of $£ 19,200$ per patient. ${ }^{4}$ Furthermore, costs can increase by more than $60 \%$ and the length of hospital stay can almost double in patients who develop DBI. ${ }^{5}$ The pooled estimates for DBI for grade IIIa, IIIb, and IIIc tibial fractures have been reported at 5\% (2.6-7.1\%), 12.3\% (9.4-15.1\%), and 16.1\% (10.2-22.0\%), respectively. ${ }^{6}$ The reported overall amputationrate is $6.2 \%(3.8-8.6 \%)$ for grade IIIb and $79.6 \%$ (64.3-95\%) for grade Illc tibial fractures. ${ }^{6}$

Reported techniques for definitive skeletal stabilisation of open tibial fractures include intramedullary nail fixation (IMF), circular

\footnotetext{
1,2Department of Plastic Surgery, Hull University Teaching Hospitals, Hull, United Kingdom

${ }^{3}$ Department of General Surgery, Bristol Hospitals NHS Trust, Bristol, United Kingdom

${ }^{4}$ Department of Infectious Diseases, Hull University Teaching Hospitals, Hull, United Kingdom

5,7Department of Trauma and Orthopaedic Surgery, Hull University Teaching Hospitals, Hull, United Kingdom

${ }^{6}$ Department of Radiology, Hull University Teaching Hospitals, Hull, United Kingdom
}

Corresponding Author: Ibrahim Natalwala, Department of Plastic Surgery, Hull University Teaching Hospitals, Hull, United Kingdom, e-mail: ibrahim.natalwala@nhs.net

How to cite this article: Natalwala I, Chuo CB, Shariatmadari I, et al. Outcomes and Incidence of Deep Bone Infection in Grade III Diaphyseal Open Tibial Fractures: Circular Fixator vs Intramedullary Nail. Strategies Trauma Limb Reconstr 2021;16(3):161-167.

Source of support: Nil

Conflict of interest: None

frame fixation (CFF), and open reduction and internal fixation. Open reduction and internal fixation has been shown to have a

(c) The Author(s). 2021 Open Access This article is distributed under the terms of the Creative Commons Attribution-Non Commercial-share alike license (https://creativecommons.org/licenses/by-nc-sa/4.0/) which permits unrestricted distribution, and non-commercial reproduction in any medium, provided you give appropriate credit to the original author(s) and the source, provide a link to the Creative Commons license, and indicate if changes were made. If you remix, transform, or build upon the material, you must distribute your contributions under the same license as original. The Creative Commons Public Domain Dedication waiver (http://creativecommons.org/publicdomain/zero/1.0/) applies to the data made available in this article, unless otherwise stated. 
high-pooled DBI rate of $11 \%$ and a low fracture union rate of $83 \%{ }^{7}$ and, therefore, is usually avoided in grade III open tibial fractures. ${ }^{8}$ The BOA-BAPRAS standards recommend IMF for diaphyseal fractures with minimal bone loss and CFF for those with greater comminution and bone loss. ${ }^{1}$ However, the optimal method of open tibial fracture fixation remains unclear with CFF potentially conferring a lower risk of DBI, ${ }^{7}$ whilst IMF may be associated with a shorter time to fracture union ${ }^{9}$ and lower risk of non-union. ${ }^{10}$ Given the considerable discordance in the optimal management of such fractures, the aim of this study was to compare the clinical outcomes for modern CFF vs IMF in the management of grade III open tibial fractures.

\section{Materials and Methods}

This was a single-centre retrospective study based at Hull University Teaching Hospitals Major Trauma Centre from January 2008 to December 2016 approved by the Quality Team (No. 2015034). All patients with grade $I I^{11}$ and AO 42 A, B, C ${ }^{12}$ open diaphyseal tibial fractures were included, whether treated with definitive CFF or IMF. Patients lost to follow-up or who underwent early amputation during the acute hospital admission were excluded.

All data were obtained from a review of electronic theatre and patient records, clinician-maintained electronic databases, and paper case-notes. Data collected included patient demographics and comorbidities; the mechanism, pattern and timing of injury; timing of fracture fixation and soft tissue reconstruction; total time to follow up; further operations; and outcomes. Our primary outcome measure was $\mathrm{DBI}$ and the secondary outcomes were delayed or non-union, secondary operations, and amputation.

DBI was defined by the presence of one or more of the confirmatory criteria outlined by Metsemakers et al.: the presence of a fistula or sinus, drainage of pus from the wound, and a minimum of two deep tissue specimens with the same phenotypic microorganism on culture. ${ }^{13}$ Quantitative histopathology of deep tissue samples was not routinely performed.

Radiological and clinical criteria were used to assess bone healing, including no pain at the fracture site, patient ability to fully weight-bear, and mature bone bridging in at least three cortices. The time from CFF application to frame removal was used as the time to bone healing.

Within the limitations of a retrospective study, patients with delayed union were defined as those who underwent secondary procedures to stimulate fracture union such as bone grafting, bone marrow aspirate concentrate (BMAC) injection, Exogen, and dynamisation by removing locking screws in the IMF group. Patients with non-union were defined as those who had fractures with delayed union requiring surgical revision of their fixation.

For confirmation of these diagnoses, the senior author reviewed the plain radiographs to assess for the lack of bone healing (despite adequate time since CFF or IMF), clinical documentation for ongoing pain or mobility at the fracture site, evidence of infection, and the nature of secondary procedures performed to achieve union.

Patients with significant bone loss refer to those who had planned bone grafting after initial definitive fixation, acute shortening (with or without subsequent lengthening), bone transport, or where clinically documented and radiologically confirmed.

Patient data were recorded using Microsoft ${ }^{\circledR}$ Excel (v16.16.3) (Redmond, USA), and statistical analyses were performed using
GraphPad Prism ${ }^{\circledast}$ (v8.0.0) (San Diego, USA). Continuous variables were tested for normality using the Shapiro-Wilk test. The CFF and IMF groups were compared using the Mann-Whitney $U$ (MWUT) or Fisher's exact test (FET) depending on whether variables were continuous or dichotomous. The Kruskal-Wallis (non-parametric) test was used to compare the median time to circular frame removal stratified by GA grade.

\section{RESULTS}

A total of 47 patients ( 48 limbs) were included in the CFF group and 23 patients (25 limbs) in the IMF group. There was no significant difference in the age and sex demographics between the two groups (Table 1), and in the number of patients with $\leq 1$ comorbidity and patients with $\geq 2$ comorbidities between the CFF and IMF groups $(p=0.23, \mathrm{FET})$.

The distribution of grade III fracture subtypes within each group is shown in Figure 1. The ratio of grade IIla to grade IIIb fractures treated in the CFF and IMF groups was not significantly different ( $p=0.12, \mathrm{FET})$. In the CFF group, three patients had acute shortening to allow their grade IIIb fracture wounds to be directly closed. For the purposes of this study, their original grade (IIIb) was used.

The median time to first debridement was 1 day [interquartile range (IQR) $0-1$ ] in the CFF group and 0 days (IQR $0-1$ ) in the IMF

Table 1: Patient demographics for CFF and IMF groups

\begin{tabular}{|c|c|c|c|c|}
\hline Demographic factor & & CFF & IMF & \\
\hline No. of patients & & 47 & 23 & - \\
\hline No. of limbs & & 48 & 25 & - \\
\hline Sex (M:F) & & $\begin{array}{l}37(79 \%): \\
10(21 \%)\end{array}$ & $\begin{array}{l}19(83 \%): \\
4(17 \%)\end{array}$ & $p>0.9999^{\dagger}$ \\
\hline $\begin{array}{l}\text { Median age } \\
\text { (interquartile range) }\end{array}$ & & $\begin{array}{l}39 \text { years } \\
(24-55)\end{array}$ & $\begin{array}{l}30 \text { years } \\
(19-41)\end{array}$ & $p=0.15^{\ddagger}$ \\
\hline No. of comorbidities & $\begin{array}{c}0 \\
1 \\
\geq 2\end{array}$ & $\begin{array}{r}31(66 \%) \\
8(17 \%) \\
8(17 \%)\end{array}$ & $\begin{array}{c}14(61 \%) \\
2(9 \%) \\
7(30 \%)\end{array}$ & \\
\hline
\end{tabular}

${ }^{\dagger} \mathrm{FET} ;{ }^{\ddagger} \mathrm{MWUT}$

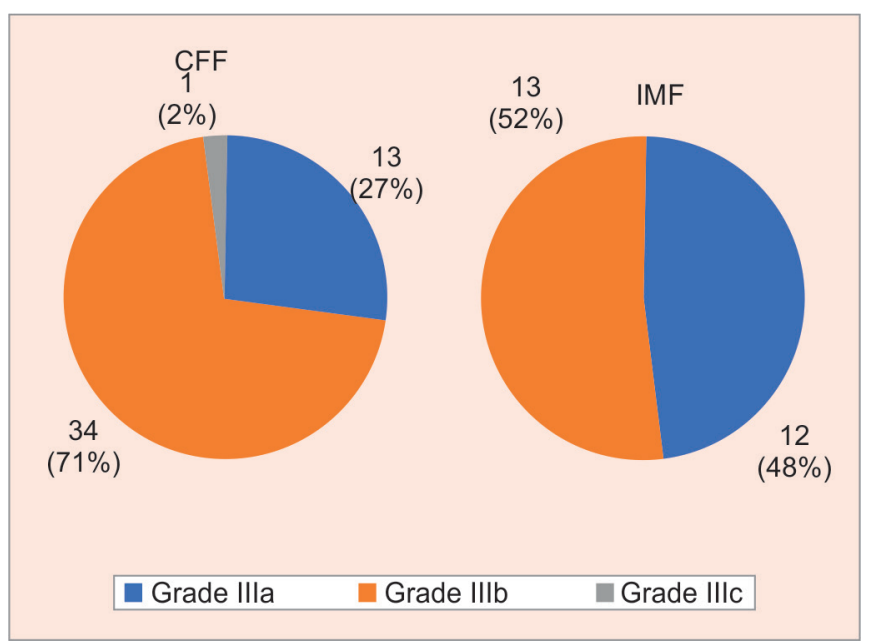

Fig. 1: Diagrams showing the distribution of grade III tibial fractures in CFF and IMF groups 
group ( $p=0.91$, MWUT). However, the median time to definitive stabilisation was significantly longer for the CFF group at 9 days (IQR 3-13) in comparison with 1 day (IQR 0-3.5) for the IMF group ( $p<0.0001$, MWUT). All circular frames were applied with the consultant present, whereas only 15 limbs (60\%) had IMF performed with the consultant present ( $p<0.0001, \mathrm{FET})$.

The majority of the frames applied were hexapod 39/48 (81\%). In the CFF group, four limbs (8\%) had definitive CFF at the time of debridement. The median time for conversion of a mono-lateral external fixator to a circular frame was 9 days (IQR 3.75-12.25). Eight limbs (32\%) in the IMF group had a mono-lateral external fixator at the initial debridement, which was converted at a mean of 5.4 days (range $2-12$ ).

There was no significant difference in the median time to soft tissue cover for the two groups: 4 days (IQR 3-6.25) for CFF and 3 days (IQR 1-7) for IMF ( $p=0.22$, MWUT). Although there was a higher percentage of free flaps performed in the CFF group ( $27 \%$ in CFF and $12 \%$ in IMF), there was no statistical difference between the two groups in the number of patients who received flap reconstruction (local and free flap) and those who did not (direct closure and skin graft reconstruction) ( $p=0.46, \mathrm{FET})$ (Fig. 2). In the CFF group, there were 13 grade Illa injuries, of which 12 had primary closure and one underwent split-thickness skin grafting (SSG). In the IMF group, 12 limbs had grade Illa injuries of which 8 had primary closure, 3 underwent SSG, and 1 underwent a local flap. One patient with grade IIIb injury had extensive periosteal stripping and managed to be successfully treated with SSG reconstruction.

Definitive fracture fixation with simultaneous definitive soft tissue reconstruction was achieved in 10 out of 34 (29\%) patients in the CFF group and 9 out of 16 (56\%) patients in the IMF group $(p=0.78, \mathrm{FET})$. The median time to circular frame removal was

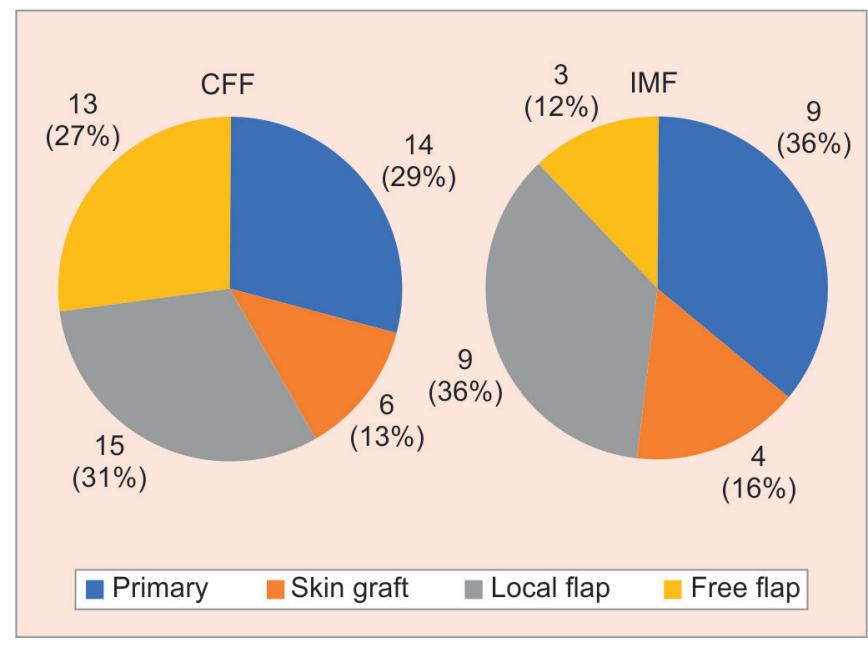

Fig. 2: Diagrams showing the different types of soft tissue reconstruction used in the CFF and IMF groups
235.5 days (IQR 170.3-431.3) and increased significantly with the severity of the injury. Limbs with fractures graded IIla, IIIb, and IIIc had frames removed at a median of 174 days (IQR 139-191.5), 268.5 days (IQR 213-450.5), and 432 days, respectively $(p=0.01$, Kruskal-Wallis test).

The median follow-up time from CFF application to final clinic visit was 730 days (IQR 581-993). The median follow-up time from IMF to final clinic visit was 548 days (IQR 136.5-937).

At follow-up, there was a significant difference in DBI with one limb affected (2\%) in the CFF group and four (16\%) in the IMF group ( $p=0.04, \mathrm{FET})$. Limbs with and without $\mathrm{DBI}$ stratified by fixation type, GA grade, and soft tissue reconstruction are shown in Table 2. In the IMF group, three patients underwent the debridement of DBI and the removal of metalwork; out of three patients, one went on to have an amputation. The fourth patient had retention of the metalwork and received suppressive oral doxycycline for chronic osteomyelitis. One patient in the CFF group had an amputation due to poor superficial wound healing only with no signs of DBI.

Non-union was diagnosed in two limbs (4\%) in the CFF group and one limb (4\%) in the IMF group ( $p>0.99$, FET). Delayed union was diagnosed in 12 limbs (25\%) in the CFF group and 4 limbs (16\%) in the IMF group ( $p=0.55, \mathrm{FET})$. Bone grafting was performed 13 times in 11 limbs (23\%) in the CFF group for delayed union and once in one limb (2\%) for non-union. In three limbs (6\%) in the CFF group, planned bone grafting after initial definitive fixation was performed for significant bone loss at the time of injury; one of these patients subsequently went on to have delayed union. In the IMF group, secondary bone grafting was performed in three limbs (12\%): one planned for primary bone loss, one following debridement of DBI, and one for non-union. Table 3 details all secondary procedures performed. There were significantly more limbs that received bone grafting for delayed or non-union in the CFF group ( $p=0.03$, FET). In the CFF group, both patients with non-union underwent revision of CFF (one of these additionally required bone grafting). One patient in the IMF group with non-union underwent exchange of IMF and bone grafting.

There were 11 limbs (23\%) with segmental fractures in the CFF group and none in the IMF group ( $p=0.01, \mathrm{FET})$ and $15 \mathrm{limbs}$ $(31 \%)$ in the CFF group with bone loss compared to one limb (4\%) in the IMF group ( $p=0.01, \mathrm{FET}$ ) (Table 4). In the CFF group, 7 of the 15 limbs with bone loss had acute shortening, and of these, one had a proximal corticotomy for bone transport, and four had lengthening; 8 other limbs had clinically documented bone loss. The remaining patient with bilateral open fractures had one side with bone transport and the other side acutely shortened without lengthening. Six of the $15 \mathrm{limbs}$ with bone loss also required a free flap for soft tissue reconstruction. In the IMF group, one limb had significant bone loss requiring reconstruction with the Masquelet technique; this patient also required a free flap for soft tissue cover.

A subgroup analysis of patients in CFF and IMF groups without bone loss or segmental fractures (surrogate features of high-

Table 2: Limbs with and without DBI stratified by fixation type, GA grade, and soft tissue reconstruction

\begin{tabular}{|c|c|c|c|c|c|c|c|c|c|c|c|c|}
\hline \multirow{3}{*}{$\begin{array}{l}\text { Type of fixation } \\
\text { GA grade } \\
\text { Soft tissue cover }\end{array}$} & \multicolumn{6}{|c|}{ CFF } & \multicolumn{6}{|c|}{ IMF } \\
\hline & \multicolumn{2}{|c|}{ IIIa } & \multicolumn{2}{|c|}{$I I I b$} & \multicolumn{2}{|c|}{ IIIC } & \multicolumn{2}{|c|}{ IIIa } & \multicolumn{2}{|c|}{$I I I b$} & \multicolumn{2}{|c|}{ IIIC } \\
\hline & Flap & No flap & Flap & No flap & Flap & No flap & Flap & No flap & Flap & No flap & Flap & No flap \\
\hline Limbs without DBI & 0 & 12 & 27 & 7 & 1 & 0 & 1 & 10 & 8 & 2 & 0 & 0 \\
\hline Limbs with DBI & 0 & 1 & 0 & 0 & 0 & 0 & 0 & 1 & 3 & 0 & 0 & 0 \\
\hline
\end{tabular}


Table 3: Secondary procedures for DBI, delayed or non-union, and limb length discrepancy in both groups (some limbs had more than one type of procedure)

\begin{tabular}{|c|c|c|c|c|c|}
\hline & \multicolumn{2}{|c|}{ CFF } & \multicolumn{2}{|c|}{ IMF } & \multirow[b]{2}{*}{ FET } \\
\hline & No. of limbs (\%) & No. of procedures & No. of limbs (\%) & No. of procedures & \\
\hline Debridement of DBI & $1(2)$ & 1 & $3(12)$ & 3 & $p=0.11$ \\
\hline Removal of infected metalwork & $1(2)$ & 1 & $3(12)$ & 3 & $p=0.11$ \\
\hline Bone grafting for delayed or non-union & $12(25)$ & 14 & $1(4)$ & 1 & $p=0.03$ \\
\hline Bone grafting for post-osteomyelitis debridement & $0(0)$ & 0 & $1(4)$ & 1 & $p=0.34$ \\
\hline Bone grafting for primary bone loss & $3(6)$ & 3 & $1(4)$ & 1 & $p>0.99$ \\
\hline BMAC/Exogen & $4(8)$ & 5 & $2(8)$ & 2 & $p>0.99$ \\
\hline Dynamisation & - & - & $3(12)$ & 3 & - \\
\hline Redo circular frame & $2(4)$ & 2 & - & - & - \\
\hline Exchange nail & - & - & $1(4)$ & 1 & - \\
\hline
\end{tabular}

Table 4: Subgroup analysis of the effect of segmental fractures or bone loss on the outcomes for CFF and IMF groups

\begin{tabular}{|c|c|c|c|c|c|c|}
\hline & \multicolumn{2}{|c|}{$\begin{array}{c}\text { Not segmental fracture and } \\
\text { no bone loss }\end{array}$} & \multirow[b]{2}{*}{ FET } & \multicolumn{2}{|c|}{ Segmental fracture or bone loss } & \multirow[b]{2}{*}{ FET } \\
\hline & CFF & IMF & & CFF & IMF & \\
\hline Total no. of limbs & 26 & 24 & & 22 & 1 & \\
\hline No. of limbs that had bone grafting & $3(12 \%)$ & $2(8 \%)$ & $p>0.99$ & $11(50 \%)$ & $1(100 \%)$ & $p>0.99$ \\
\hline No. of limbs with delayed or non-union & $4(15 \%)$ & $5(21 \%)$ & $p=0.72$ & $10(46 \%)$ & $0(0 \%)$ & $p>0.99$ \\
\hline No of limbs with DBI & $1(4 \%)$ & $3(13 \%)$ & $p=0.34$ & $0(0 \%)$ & $1(100 \%)$ & $p=0.04$ \\
\hline
\end{tabular}

energy transfer) showed no significant difference in the delayed or non-union rates ( $p=0.72 \mathrm{FET}$ ) and no significant difference in $\mathrm{DBI}(p=0.34, \mathrm{FET})$.

\section{Discussion}

In our study, the DBI rate in the CFF group was significantly lower than the IMF group ( 2 vs $16 \%, p=0.04$ ), despite more limbs with segmental fractures $(p=0.01)$ or bone loss $(p=0.01)$, and a longer time from debridement to CFF [9 days (IQR 3-13 days)] ( $p<0.0001)$. Our low infection rate is in keeping with the reported literature (7). Patients with the longest delays to CFF were those transferred either from peripheral hospitals or from overseas.

\section{Primary Outcome}

The higher incidence of DBI in the IMF group in our study is likely multifactorial. The tibial diaphysis has significantly fewer extra-osseous vessels in comparison with the proximal and distal tibial metaphyses. ${ }^{14}$ The diaphysis is therefore particularly at risk in high-energy open tibial fractures where periosteal stripping can result in significant areas of devascularisation around the fracture site due to the disruption of the periosteal blood supply. Intramedullary nailing will potentially further compromise the endosteal blood supply.

Smith et al. showed that reamed IMF significantly reduced endosteal blood supply compared to external frame fixation at all time points in a canine tibial fracture model. ${ }^{15}$ Schemitsch et al. demonstrated in a sheep tibial fracture model that reamed IMF reduced the tibial cortical bone perfusion to just $8 \%$ of pre-fracture values, although there was less reduction in the unreamed IMF group (35\% of pre-fracture values). ${ }^{16} \mathrm{~A}$ subsequent study by the same authors showed that although the endosteal blood supply of the tibia was significantly reduced by reaming, the vascularity of the callus was not affected, and at 3 months, the early union strength was the same in the reamed and unreamed groups. ${ }^{17}$ Although unreamed IMF has been associated with a higher risk of non-union, ${ }^{18}$ a recent meta-analysis by Shao et al. showed no statistically significant difference in union rate and DBI outcomes between reamed vs unreamed IMF in open tibial fractures. $^{19}$

Whilst there may be little difference in outcomes between reamed or unreamed IMF in open tibial fractures, both techniques have a higher reported rate of DBI in the literature 8.7 and $7.1 \%$, respectively) compared to $0.9 \%$ for $C F F$, with a possible factor being the degree of damage to the endosteal blood supply. ${ }^{7}$

In the CFF group, there were two total flap failures, but neither went on to develop DBI. Four patients in the IMF group had a flap complication (haematoma or flap loss) of whom three went on to develop DBI. These three patients all had debridement and monolateral external fixation (Ex-Fix) first followed by definitive fracture fixation with simultaneous soft tissue reconstruction at days 2, 8, and 12. Flap failure in these patients resulted in the presence of necrotic soft tissue around the fracture site, wound breakdown, and potential exposure of the internal metalwork. This bacteria-friendly environment along with decreased local soft tissue and cortical perfusion due to IMF were also likely contributing factors. ${ }^{20,21}$

Furthermore, a delay in conversion from mono-lateral Ex-Fix to IMF may be a risk factor for DBI. ${ }^{22}$ The BOA-BAPRAS standards state that whilst there is no definitive evidence, conversion from temporary Ex-Fix to IMF is recommended to be within the first 72 hours.' Patients in our study had mono-lateral Ex-Fix converted to IMF after a mean of 5.4 (2-12) days, which is 2 days longer than recommended.

\section{Secondary Outcomes}

The definition of delayed and non-union is a continued source of debate and will vary from surgeon to surgeon and with the nature of the injury. The rate of delayed union was higher in the CFF group (25\%) compared to the IMF group (16\%). This may be due to a bias 
towards CFF for more severe injuries or may be due to the incentive to achieve union and frame removal (vs the ability for a patient with IMF to continue weight-bearing during fracture union). More limbs required bone grafting for delayed and non-union in the CFF group $(p=0.03)$. A subgroup analysis of the CFF group showed that $22(46 \%)$ limbs with bone loss or segmental fractures had a higher incidence of delayed or non-union ( $p=0.03, \mathrm{FET})$ and bone grafting ( $p=0.005$, FET) compared to limbs without these injury patterns. This supports other evidence that these injury patterns are risk factors for delayed and non-union. ${ }^{23}$

The reason more limbs went on to secondary bone grafting in the CFF group may be that $46 \%$ of limbs had segmental injuries or bone loss at presentation, which are significantly more severe injury patterns associated with greater bone devascularisation. In contrast, there were no segmental fractures that were treated with IMF in our study. The difference in the proportion of limbs with these injuries in the CFF vs IMF groups may suggest a justifiable selection bias for treatment, which is recommended in the BOA-BAPRAS standards that state fractures with significant bone loss or complex multilevel fractures are more appropriately treated with CFF.

\section{Literature Review}

Six meta-analyses were identified that compared IMF to external fixation ${ }^{9,10,24-27}$ (Table 5). All studies had at least one outcome favouring IMF. Results of the meta-analyses should be interpreted with caution as some studies used varying GA grades in their inclusion criteria (some did not include IIIb and $\mathrm{IIC}^{28}$ and others included I and II). ${ }^{29-31}$ The majority of meta-analyses included only a small number of patients, and studies from 30 years ago ${ }^{29,30}$ were included that used obsolete devices such as Ender nails. Most of the studies included in the meta-analyses used mono-lateral frames and not circular frames. ${ }^{32}$ Furthermore, there was variation between studies in whether superficial or pin tract infections were included in the outcome analyses. Our study includes only grade III fractures managed with stable circular fixators and modern intramedullary nails.

A recent network meta-analysis by Foote et al. measured significant unplanned reoperation rates (for DBI, implant failure, loss of fixation, non-union, and malunion) and found that unreamed IMF resulted in fewer unplanned reoperations compared to external fixation with a network odds ratio (OR) $0.38 ; 95 \%$ confidence interval (Cl) $(0.23-0.62 ; p<0.05) .{ }^{33}$ However, the studies included compared mono-lateral Ex-Fix to IMF and did not include modern CFF. They found that literature comparing CFF to IMF was not available and that indirect evidence was of very low confidence. ${ }^{33} \mathrm{~A}$ study by Inan et al. was not included in the network meta-analysis and is the only other paper that directly compares CFF to IMF but includes GA Illa fractures only. ${ }^{28}$

Table 5: Summary of the meta-analyses comparing IMF and external fixation

\begin{tabular}{|c|c|c|c|c|c|c|c|c|c|}
\hline \multirow{2}{*}{$\begin{array}{l}\text { Meta- } \\
\text { analyses }\end{array}$} & \multirow[b]{2}{*}{ RCTs } & \multicolumn{2}{|c|}{ Number of patients } & \multirow{2}{*}{$\begin{array}{l}\text { Superficial } \\
\text { infection }\end{array}$} & \multirow{2}{*}{$\frac{D B I}{-}$} & \multirow[b]{2}{*}{ Time to union } & \multirow{2}{*}{$\begin{array}{l}\text { Delayed } \\
\text { union }\end{array}$} & \multirow[b]{2}{*}{ Malunion } & \multirow{2}{*}{$\frac{\text { Non-union }}{-}$} \\
\hline & & $I M F$ & External fixation & & & & & & \\
\hline \multirow[t]{2}{*}{ Dervin 1996} & Henley 1994 & 12 & 14 & 0.29 & \multirow[t]{2}{*}{-} & -5.28 & \multirow[t]{2}{*}{-} & 0.37 & \multirow[t]{2}{*}{-} \\
\hline & Tornetta 1993 & 15 & 14 & $(0.07,1.20)$ & & $\begin{array}{l}\text { (-7.84, }-2.72) \\
\text { Favouring IMF }\end{array}$ & & $(0.07,2.73)$ & \\
\hline \multirow{5}{*}{$\begin{array}{l}\text { Bhandari } \\
2001^{\dagger}\end{array}$} & Henley 1998 & 104 & 70 & 0.24 & \multirow{5}{*}{$\begin{array}{c}0.60 \\
(0.36,1.01)\end{array}$} & - & \multirow[t]{5}{*}{ - } & 0.42 & \multirow{5}{*}{$\begin{array}{c}0.69 \\
(0.46,1.03)\end{array}$} \\
\hline & Tornetta 1993 & 15 & 14 & $(0.08,0.73)$ & & & & $(0.25,0.71)$ & \\
\hline & Tu 1995 & 18 & 18 & Favouring & & & & Favouring & \\
\hline & Swanson 1990 & 50 & 50 & $I M F$ & & & & $I M F$ & \\
\hline & Holbrook 1989 & 29 & 28 & & & & & & \\
\hline \multirow[t]{12}{*}{ Fang 2012} & Holbrook 1989 & 29 & 28 & - & \multirow{12}{*}{$\begin{array}{c}0.83 \\
(0.44,1.55)\end{array}$} & -0.07 & \multirow[t]{12}{*}{ - } & 2.06 & \multirow{12}{*}{$\begin{array}{c}1.39 \\
(0.74,2.62)\end{array}$} \\
\hline & Whitelaw 1990 & 6 & 14 & & & $(-4.65,4.52)$ & & $(1.05,4.06)$ & \\
\hline & Tornetta 1993 & 15 & 14 & & & & & Favouring & \\
\hline & Tu 1995 & 18 & 18 & & & & & $I M F$ & \\
\hline & Schandelmaier 1997 & 17 & 15 & & & & & & \\
\hline & Alberts 1999 & 17 & 10 & & & & & & \\
\hline & Jiang 2000 & 16 & 17 & & & & & & \\
\hline & Shannon 2002 & 13 & 17 & & & & & & \\
\hline & Fan 2004 & 34 & 22 & & & & & & \\
\hline & Kaftandziev 2006 & 18 & 30 & & & & & & \\
\hline & Inan 2007 & 29 & 32 & & & & & & \\
\hline & Rohde 2007 & 20 & 18 & & & & & & \\
\hline \multirow{5}{*}{$\begin{array}{l}\text { Giovannini } \\
2016\end{array}$} & Holbrook 1989 & 29 & 28 & - & \multirow{5}{*}{$\begin{array}{c}0.48 \\
(0.24,0.93) \\
\text { Favouring IMF }\end{array}$} & - & \multirow[t]{5}{*}{ - } & \multirow{5}{*}{\multicolumn{2}{|c|}{$\begin{array}{c}0.41(0.21,0.81)^{\ddagger} \\
\text { Favouring IMF }\end{array}$}} \\
\hline & Inan 2007 & 29 & 32 & & & & & & \\
\hline & Mohseni 2011 & 25 & 25 & & & & & & \\
\hline & Tornetta 1993 & 15 & 14 & & & & & & \\
\hline & Tu 1995 & 18 & 18 & & & & & & \\
\hline \multirow[t]{6}{*}{ Zhang 2016} & Tornetta 1993 & 15 & 14 & 0.39 & \multirow{6}{*}{$\begin{array}{c}1.07 \\
(0.43,2.63)\end{array}$} & -1.01 & \multirow{6}{*}{$\begin{array}{l}2.26 \\
(0.73 \\
7.00)\end{array}$} & 0.27 & 0.68 \\
\hline & Tu 1995 & 18 & 18 & $(0.17,0.87)$ & & $(-1.43,-0.59)$ & & $(0.09,0.78)$ & $(0.22,2.11)$ \\
\hline & Schandelmaier 1997 & 17 & 15 & Favouring & & Favouring IMF & & Favouring & \\
\hline & Alberts 1999 & 17 & 10 & $I M F$ & & & & $I M F$ & \\
\hline & Jiang 2000 & 16 & 17 & & & & & & \\
\hline & Rohde 2007 & 20 & 18 & & & & & & \\
\hline
\end{tabular}


Table 5: (Contd...)

\begin{tabular}{|c|c|c|c|c|c|c|c|c|c|}
\hline \multirow{2}{*}{$\begin{array}{l}\text { Meta- } \\
\text { analyses }\end{array}$} & \multirow[b]{2}{*}{ RCTs } & \multicolumn{2}{|c|}{ Number of patients } & \multirow{2}{*}{$\begin{array}{c}\text { Superficial } \\
\text { infection }\end{array}$} & \multirow{2}{*}{$\begin{array}{c}D B I \\
-\end{array}$} & \multirow[b]{2}{*}{ Time to union } & \multirow{2}{*}{$\begin{array}{c}\text { Delayed } \\
\text { union }\end{array}$} & \multirow[b]{2}{*}{ Malunion } & \multirow{2}{*}{$\begin{array}{c}\text { Non-union } \\
-\end{array}$} \\
\hline & & $I M F$ & External fixation & & & & & & \\
\hline \multirow[t]{6}{*}{ Fu 2018} & Holbrook 1989 & 29 & 28 & 5.13 & 1.68 & - & 1.35 & 2.99 & 0.90 \\
\hline & Tornetta 1993 & 15 & 14 & $(2.56$ & $(0.73,3.87)$ & & (0.79, & $(1.87,4.79)$ & $(0.45,1.78)$ \\
\hline & Tu 1995 & 18 & 18 & $10.28)$ & & & $2.31)$ & Favouring & \\
\hline & Henley 1998 & 104 & 70 & Favouring & & & & IMF & \\
\hline & Inan 2007 & 29 & 32 & $I M F$ & & & & & \\
\hline & Mohseni 2011 & 25 & 25 & & & & & & \\
\hline \multirow[t]{2}{*}{ Our study } & & Nur & iber of patients & $\begin{array}{c}\text { Superficial } \\
\text { infection }\end{array}$ & $D B I$ & Time to union & $\begin{array}{c}\text { Delayed } \\
\text { union }\end{array}$ & Malunion & Non-union \\
\hline & & IMF & CFF & & & & & & \\
\hline $\begin{array}{l}\text { Natalwala } \\
\text { et al. }\end{array}$ & & 23 & 47 & - & $\begin{array}{c}9.68 \\
(1.39,120.5) \\
p=0.04 \\
\text { Favouring CFF }\end{array}$ & - & $\begin{array}{c}0.69 \\
(0.22 \\
2.52) \\
p=0.76\end{array}$ & - & $\begin{array}{c}1.02 \\
(0.07,9.16) \\
p>0.9999\end{array}$ \\
\hline
\end{tabular}

Outcomes were expressed as OR except ${ }^{\dagger}$ (expressed as relative risk). Giovannini et al. reported a single OR for malunion and non-union ${ }^{\ddagger}$

Given the limitations of the studies used in the meta-analyses and network meta-analysis, our study is highly relevant in the current era as we now work within a national framework following the publication of the BOA/BAPRAS standards. Furthermore, our study directly compares outcomes of CFF and IMF in high-energy GA Illa-c tibial fractures.

\section{Limitations}

Our study has an observational retrospective design, which is subject to confounding factors, e.g., indication to treat. Higher energy fracture patterns (segmental fractures or those with significant bone loss) were more likely to undergo CFF to enable more options for secondary procedures such as bone grafting and limb lengthening or bone transport. Furthermore, any delay in presentation or transfer to our unit, or delay in soft tissue cover could have potentially influenced the choice of fixation.

The group sizes are small with relatively fewer numbers of patients in the IMF cohort. We have a well-established limb reconstruction unit, and therefore, all CFFs are done by experts. However, IMF is undertaken by a wider surgical group including trainees in $40 \%$ of cases, without consultant supervision. This may produce inherent bias in the outcome. It is likely that this bias also exists in other orthoplastic units where CFF or IMF may be favoured, depending on the skills and experience of the members of these units. We recognise that an individual surgeon's expertise may influence the fixation options offered to manage these injuries. For these reasons, the results of this study should be interpreted with caution.

\section{ConCLUSION}

In this study of GA grade III open tibial fractures, limbs treated with CFF had a significantly lower incidence of DBI compared to IMF. CFF was overall associated with a significantly greater incidence of subsequent bone grafting for delayed or non-union. However, a subgroup analysis of patients without segmental fractures or bone loss showed that there was no significant difference in outcomes.

Adequately powered multicentre randomised controlled trials are required to further ascertain differences in outcomes between CFF and IMF, particularly in patients without highenergy fracture patterns. We would recommend the use of CFF for the management of grade III diaphyseal open tibial fractures particularly with high-energy fracture patterns (bone loss and segmental) to minimise DBI.

\section{References}

1. Eccles S, Handley B, Khan U, et al. Standards for the management of open fractures. Oxford: Oxford University Press, 2020.

2. Court-Brown CM, Bugler KE, Clement ND, et al. The epidemiology of open fractures in adults. A 15-year review. Injury 2012;43(6):891-897. DOI: 10.1016/j.injury.2011.12.007.

3. Morgenstern M, Vallejo A, McNally MA, et al. The effect of local antibiotic prophylaxis when treating open limb fractures: a systematic review and meta-analysis. Bone Joint Res 2018;7(7): 447-456. DOI: 10.1302/2046-3758.77.BJR-2018-0043.R1.

4. Tissingh EK, Memarzadeh A, Queally J, et al. Open lower limb fractures in major trauma centers - a loss leader? Injury 2017;48(2):353-356. DOI: 10.1016/j.injury.2016.12.017.

5. Olesen UK, Pedersen NJ, Eckardt $\mathrm{H}$, et al. The cost of infection in severe open tibial fractures treated with a free flap. Int Orthop 2017;41(5):1049-1055. DOI: 10.1007/s00264-016-3337-6.

6. Papakostidis C, Kanakaris NK, Pretel J, et al. Prevalence of complications of open tibial shaft fractures stratified as per the Gustilo-Anderson classification. Injury 2011;42(12):1408-1415. DOI: 10.1016/j.injury.2011.10.015.

7. Dickson DR, Moulder E, Hadland Y, et al. Grade 3 open tibial shaft fractures treated with a circular frame, functional outcome and systematic review of literature. Injury 2015;46(4):751-758. DOI: 10.1016/j.injury.2015.01.025.

8. Mundi R, Chaudhry H, Niroopan G, et al. Open tibial fractures: updated guidelines for management. JBJS Rev 2015;3(2):1-7. DOI: 10.2106/JBJS. RVW.N.00051.

9. Zhang F, Zhu Y, Li W, et al. Unreamed Intramedullary Nailing is a better alternative than External Fixator for Gustilo grade IIIB Tibial Fractures based on a meta-analysis. Scand J Surg 2016;105(2):117-124. DOI: $10.1177 / 1457496915586649$.

10. Fu Q, Zhu L, Lu J, et al. External fixation versus unreamed tibial intramedullary nailing for open tibial fractures: a meta-analysis of randomized controlled trials. Sci Rep 2018;8(1):12753. DOI: 10.1038/ s41598-018-30716-y.

11. Gustilo RB, Mendoza RM, Williams DN. Problems in the management of type III (Severe) open fractures. J Trauma Inj Infect Crit Care 1984;24(8):742-746. DOI: 10.1097/00005373-198408000-00009.

12. Repo J. Microvascular reconstruction of traumatic compound bone and soft tissue defects of the tibia and ankle: long-term patient- 
reported outcomes. 2017. Available from: https://helda.helsinki.fi/ bitstream/handle/10138/169990/MICROVAS.pdf?sequence=1.

13. Metsemakers WJ, Morgenstern M, McNally MA, et al. Fracturerelated infection: a consensus on definition from an international expert group. Injury 2018;49(3):505-510. DOI: 10.1016/j.injury.2017. 08.040 .

14. Borrelli J, Prickett W, Song E, et al. Extraosseous blood supply of the tibia and the effects of different plating techniques: a human cadaveric study. J Orthop Trauma 2002;16(10):691-695. DOI: 10.1097/00005131-200211000-00002.

15. Smith SR, Bronk JT, Kelly PJ. Effect of fracture fixation on cortical bone blood flow. J Orthop Res 1990;8(4):471-478. DOI: 10.1002/ jor.1100080402.

16. Schemitsch EH, Kowalski MJ, Swiontkowski MF, et al. Cortical bone blood flow in reamed and unreamed locked intramedullary nailing: a fractured tibia model in sheep. J Orthop Trauma 1994;8(5):373-382. DOI: 10.1097/00005131-199410000-00002.

17. Schemitsch EH, Kowalski MJ, Swiontkowski MF, et al. Comparison of the effect of reamed and unreamed locked intramedullary nailing on blood flow in the callus and strength of union following fracture of the sheep tibia. J Orthop Res 1995;13(3):382-389. DOI: 10.1002/jor. 1100130312.

18. Xia L, Zhou J, Zhang Y, et al. A meta-analysis of reamed versus unreamed intramedullary nailing for the treatment of closed tibial fractures. Orthopedics 2014;37(4):e332. DOI: 10.3928/0147744720140401-52.

19. Shao Y, Zou H, Chen S, et al. Meta-analysis of reamed versus unreamed intramedullary nailing for open tibial fractures. J Orthop Surg Res 2014;9:74. DOI: 10.1186/s13018-014-0074-7.

20. Tornetta $P$ 3rd, DeMarco C. Intramedullary nailing after external fixation of the tibia. Bull Hosp Jt Dis 1995;54(1):5-13. PMID: 8541783.

21. Yokoyama K, Uchino M, Nakamura K, et al. Risk factors for deep infection in secondary intramedullary nailing after external fixation for open tibial fractures. Injury 2006;37(6):554-560. DOI: 10.1016/j. injury.2005.08.026.

22. Bhandari M, Zlowodzki $M$, Tornetta $P$, et al. Intramedullary nailing following external fixation in femoral and tibial shaft fractures.J Orthop Trauma 2005;19(2):140-144. DOI: 10.1097/00005131-20050200000012.
23. Santolini E, West R, Giannoudis PV. Risk factors for long bone fracture non-union: a stratification approach based on the level of the existing scientific evidence. Injury 2015;46:S8-S19. DOI: 10.1016/ S0020-1383(15)30049-8.

24. Dervin GF. Skeletal fixation of grade IIIB tibial fractures: The potential of metaanalysis. Clin Orthop Relat Res 1996;(332):10-15. DOI: 10.1097/00003086-199611000-00003.

25. Fang X, Jiang L, Wang Y, et al. Treatment of Gustilo grade III tibial fractures with unreamed intramedullary nailing versus external fixator: a meta-analysis. Med Sci Monit 2012;18(4):RA49-RA56. DOI: $10.12659 / \mathrm{msm} .882610$.

26. Giovannini $F$, de Palma L, Panfighi A, et al. Intramedullary nailing versus external fixation in Gustilo type III open tibial shaft fractures: a meta-analysis of randomised controlled trials. Strategies Trauma Limb Reconstr 2016;11(1):1-4. DOI: 10.1007/s11751-016-0245-7.

27. Bhandari M, Guyatt GH, Swiontkowski MF, et al. Treatment of open fractures of the shaft of the tibia. J Bone Jt Surg - Ser B 2001;83(1): 62-68. DOI: 10.1302/0301-620x.83b1.10986.

28. Inan $M$, Halici M, Ayan I, et al. Treatment of type IIIA open fractures of tibial shaft with llizarov external fixator versus unreamed tibial nailing. Arch Orthop Trauma Surg 2007;127(8):617-623. DOI: 10.1007/ s00402-007-0332-9.

29. Whitelaw G, Wetzler M, Nelson A, et al. Ender rods versus external fixation in the treatment of open tibial fractures. Clin Orthop Relat Res 1990;(253):258-269. PMID: 2317982.

30. Holbrook JL, Swiontkowski MF, Sanders R. Treatment of open fractures of the tibial shaft: ender nailing versus external fixation. A randomized, prospective comparison. J Bone Jt Surg Am 1989;71(8):1231-1238. PMID: 2777852.

31. Alberts KA, Loohagen $G$, Einarsdottir $H$. Open tibial fractures: faster union after unreamed nailing than external fixation. Injury 1999;30(8):519-523. DOI: 10.1016/s0020-1383(99)00143-6.

32. Mohseni MA, Soleimanpour J, Mohammadpour $\mathrm{H}$, et al. AO tubular external fixation vs unreamed intramedullary nailing in open grade IIIA-IIIB tibial shaft fractures: a single-center randomized clinical trial. Pakistan J Biol Sci 2011;14(8):490-495. DOI: 10.3923/pjbs.2011.490.495

33. Foote $\mathrm{CJ}$, Guyatt $\mathrm{GH}$, Vignesh KN, et al. Which surgical treatment for open tibial shaft fractures results in the fewest reoperations? A network meta-analysis. Clin Orthop Relat Res 2015;473(7):2179-2192. DOI: 10.1007/s11999-015-4224-y. 